\title{
Beyond Members: Another Level of Community
}

There is no end to the accolades one could bestow on Bill Jordan for his thinking and writings about ecological restoration. To name but a few of Bill's accomplishments, there is the founding of this journal in 1981, his pioneering efforts with John Rieger and others that led to the establishment of the Society for Ecological Restoration, his organizing and editing of Restoration Ecology: A Synthetic Approach to Ecological Research, and certainly his 20 years of editorials in this very space where he probed the essence of what it means to be an ecological restorationist in our post-modern world.

From a personal perspective, Bill not only helped me better understand the principles of ecological restoration, he served as a valued mentor for my writing and editing efforts. So it is with no small amount of anxiety that I enter into this space-Bill's spaceand attempt to fill it with my own voice and ideas. And it is with no less amount of uneasiness that I write my first editorial as an earnest departure from one important tenet of Bill's philosophyhis concept of community and who belongs to a community.

My argument with Bill stems from his editorial, "Citizenor Member?," which ran in the last issue of Ecological Restoration. More to the point, my disagreement focuses on what I regard as the exclusionary nature of Bill's interpretation of community, which he summarized with the following sentence: "One is...a citizen of a state or nation, but can be a member only of a community." I think this a rather narrow, and more problematically, an elitist view of community in both a real and a theoretical sense. Moreover, I think it describes only one level at which community operates.

Bill's definition of community, as I see it, exhibits a sense of sameness, where there is little room for diverse voices, and everyone is conditioned by the same experiences and rituals. It is like a club, a political party, or a network where everyone is generally in agreement, where everyone is generally supportive and encouraging. It's a level of community and community building where a group of people establishes an esprit de corp, where they develop and engage in community that is based on a singular idea or goal-in our case, ecological restoration. This is not necessarily unhealthy. In fact, it is a wonderful and necessary ideal for any group. If, however, the group remains only inward-looking it will never rise to, or learn how to live with, the level of community where multiple ideas and values exist. It is that level of community that I think is most important to understand, and which I want to discuss.

I view community as a diverse collection of people who live in proximity to one another by choice or by fate, whose views on a variety of things may be dissimilar, and who must identify their common problems, develop consensus, and work out their differences as best they can for the mutual good of all. Obviously, this is a community where conflict and collaboration reside side-byside, where people toil to resolve the issues of their day. It is also a community where people, if they are truly engaged, come to realize the shame that we all must bear for having different voices and values. Yet, once this realization occurs, often through some kind of all-encompassing crisis or project, such as the environmental degradation of an area, the community develops strategies to help it work through its difficulties, and experience life as best it can. In this community the people are both citizens and members, and those that are privileged with the knowledge of something important to the community are held responsible for acting responsibly towards others and suggesting ways to use their knowledge wisely.

To return for a moment to Reid Helford's chapter in Restoring Nature, which was the jumping off point for Bill's editorial, I think it's clear that restorationists who become involved in communitybased restorations, and the public discussions that are a necessary part of them, have to act responsibly. Having a restorationist, as Helford recounts, tell someone who disagrees with their point of view to "shut up and sit down because you don't know what you're talking about" is not going to cut it and, in fact, will engender the same response that Helford records, "Nobody tells me to shut up and sit down. I am a citizen. I have a right to say what I feel." This is exactly the distinction Bill attempted to raise in his editorialthe difference between member and citizen. From my perspective, however, this separation is a recipe for exclusion and conflict rather than recognition of the "other" and collaboration.

I not only believe that it is important for restorationists to recognize these different levels of community, I think that it is their responsibility to help their fellow community members recognize them as well. We must learn to be equally adept at talking with our neighbors about an upcoming project as we are at preparing the site for planting. We need to establish a sense of community that embraces the concept of "stewardship across boundaries" - that is, we need to recognize that our restoration work influences those inside and outside the administrative boundaries of our project site or management area, and that their understanding and support of our work will influence the success of what it is we are trying to accomplish.

I recently attended a conference about exotic plants where I heard that members of the Florida Nursery Growers and members of the Florida Exotic Pest Plant Council have worked together to 
develop a state-wide policy to stop the sale of invasive plants in Florida. This is just one of numerous, wonderful examples of community-based efforts throughout the country where restorationists and others have found common ground and have worked together successfully as neighbors and community members. We have featured several of these projects as well as the problems restorationists have encountered in Chicago, and we will continue to do so.

As restoration moves increasingly into the public realm, our understanding of social issues, including how to recognize the power we have and share it with others, will help our group become an important and respected part of the larger community.

This issue marks a new era for Ecological Restoration and while this first editorial focuses on the social aspect of restoration, I have every intention of making every aspect of this journal-research reports, philosophical papers, conference reports, technical articles, book reviews, and the rest-accessible and pertinent to the practitioner. To that end, you can help by contacting us about your projects, the books you would like us to review, the new tools you've tried, and the problems - social, philosophical, and technical-that you've encountered.

I also want to introduce Mary Ann Pels as our Associate Editor. Mary Ann worked with Bill and me for the past three years as our abstractor and brings that experience along with a very extensive background in writing and editing to her new position. She is a joy to work as I'm sure you will learn if you talk with her on the telephone, work with her on a note, or meet her at a conference.

I have to go. They need an extra person on the burn crew.

Dave Egan 